\title{
Breves considerações sobre "Os lugares dos historiadores e da história na sociedade brasileira"
}

\section{Brief considerations on "Places of historians and history in Brazil"}

\section{Caroline Silveira Bauer}

caroline.bauer@ufrgs.br

Professora Adjunta 1-A

Universidade Federal do Rio Grande do Sul

Avenida Bento Gonçalves, 9500 - Prédio 43311, Sala 222

91509-900 - Porto Alegre - Rio Grande do Sul

Brasil

Palavras-chave

História do tempo presente; Historiografia brasileira; História da historiografia.

Keywords

History of present time; Brazilian historiography; History of Historiography. 
Embora os questionamentos sobre a função social e as utilidades do conhecimento histórico nunca tenham abandonado os historiadores, considero que nos últimos anos essas preocupações adquiriram outros contornos, e não deixaram de ser expressas nas temáticas dos Simpósios Nacionais de História, promovidos pela ANPUH. Às vésperas da realização de mais uma edição, em 2017, com a temática "Contra os preconceitos: história e democracia", vejo uma continuidade nas inquietações da área, pelo menos, desde 2013, quando um mês após a eclosão das jornadas de junho, realizou-se em Natal o simpósio - coincidentemente intitulado "Conhecimento histórico e diálogo social" - que definiu o tema e a agenda para os dois anos seguintes: "Lugares dos historiadores: velhos e novos desafios".

Realizando uma rápida retrospectiva, no interregno entre as edições de 2013 e 2015, além dos desdobramentos das manifestações de 2013, houve a rememoração dos 50 anos do golpe civil-militar de 31 de março de 1964, a realização de eleições presidenciais em uma conjuntura de extrema polarização política, o desenvolvimento dos trabalhos e a entrega do relatório da Comissão Nacional da Verdade (CNV), e os primeiros rumores sobre a possibilidade de impeachment da então presidenta, legitimamente eleita, Dilma Rousseff. E esta foi apenas a conjuntura nacional; no mundo, guerra na Síria e a destruição de patrimônios históricos mundiais, crise entre Ucrânia e Rússia, genocídio na Nigéria, atentados terroristas em Paris, e o avanço do Estado Islâmico, são apenas alguns exemplos destes dois anos que mais parecem terem comportado duas décadas.

168 Assistimos atônitos - muitas vezes, em tempo real - a reconfiguração dos tempos da justiça e da política, anteriormente marcados por um ritmo mais estável, lento; a justiça, a partir de uma série de medidas imediatistas, instrumentalizada pela mídia e pelos outros poderes; a política, pelo descaso com a democracia ou as regras do jogo democrático. Nesta conjuntura nacional e internacional que questionava certezas consideradas inabaláveis, me pareceu extremamente oportuno que a conferência de abertura do XXVIII Simpósio Nacional de História, realizado Florianópolis em julho de 2015, proferida pelo então presidente da entidade, Rodrigo Patto Sá Motta, se intitulasse "Os lugares dos historiadores e da história na sociedade brasileira" e suscitasse o debate sobre nossa função social como historiadores e nosso posicionamento frente a esses episódios.

Meu objetivo com este comentário é debater alguns aspectos apresentados por Rodrigo, mais que apresentar discordâncias sobre sua fala, que considerei bastante adequada para a ocasião e correspondente ao lugar que o conferencista ocupava. Tratam-se mais de complementações ao debate instaurado sobre os lugares que os historiadores têm ocupado, ou devem ocupar.

Patto apresenta em sua conferência três espaços em que, em seu ponto de vista, entrecruzam-se as dimensões acadêmico-profissionais e ético-sociais dos historiadores: em nível representativo, na própria ANPUH; no espaço público; e nas escolas.

Nas últimas décadas houve um crescimento exponencial do número de cursos de graduação e pós-graduação em história e, por consequência, no contingente 
de alunos e profissionais que se formam todos os anos. Esse movimento fez com que a ANPUH, para além das defesas particulares de interesses enquanto entidade representativa, reafirmasse uma perspectiva política ao enfrentar desafios como a regulamentação da profissão do historiador - uma temática na qual não existe consenso entre os profissionais.

Neste primeiro ponto, as novidades são mais conjunturais que de atuação ou epistemológicas. O grande desafio para a instituição nos últimos anos, do meu ponto de vista, tem sido repensar-se e se indagar quanto à possibilidade de unicidade representativa frente à proliferação de outras organizações, nacionais e internacionais, mais próximas às temáticas de trabalho dos historiadores.

Quanto o espaço público, embora a presença de historiadores em espaços fora da academia ou no âmbito escolar não seja nenhuma novidade, tendo, inclusive, fomentado debates sobre a pertinência de uma interferência baseada na figura de autoridade ou da expertise (HABERMAS 2001), essa discussão tem adquirido novas significações na atual conjuntura, não somente sobre as indagações quanto a este lugar, que Rodrigo se refere como "aos espaços e locais de circulação de ideias e opiniões, em especial as mídias tradicionais e as novas redes sociais", além de "outras esferas e sociabilidades" (MOTTA 2016, p. 325); mas pelas demandas sociais encaminhadas aos historiadores e pelo novo projeto para a educação pública no Brasil, que será discutido posteriormente.

Esse debate parece ter extrapolado os antigos limites da discussão sobre os ofícios do historiador e do jornalista, para centrar-se na temática da divulgação histórica, da existência de outros saberes históricos que não o escolar e o acadêmico, dos nichos editoriais e outras questões mercadológicas, da demanda por consumo de história, etc. Além dessas problemáticas, que vinculam-se diretamente à atuação profissional, existem as implicações cívicas, éticas e morais do posicionamento dos historiadores na esfera pública.

Concordo plenamente com Patto quando afirma que essas dimensões acadêmico-profissionais e ético-sociais dos historiadores estão indissociavelmente ligadas a um posicionamento político.

Em suas palavras,

Por esse roteiro chegamos ao lugar político da história. Eis aí uma questão essencial: a política e o político estão inextricavelmente implicados na nossa disciplina. É impossível desconectar o conhecimento histórico da política, afinal, o nosso campo de saber nasceu no calor das disputas políticas e fortemente ligado ao Estado, que sempre se ocupou dos discursos e representações sobre o passado, invariavelmente tentando controla-los. Em séculos recentes, ou melhor, em décadas recentes, felizmente alcançamos condições de produção do conhecimento em clima de liberdade, inclusive com a possibilidade de criticarmos o Estado - e como criticamos! Mas, isso não significou uma redução do lugar político ocupado pela história. Ao contrário, o nosso campo continua tão imerso nas disputas políticas como sempre esteve. A diferença é que hoje há mais espaço para divergências e controvérsias, mais liberdade (MOTTA 2016, p. 326).

Complementaria essa observação salientando a relação que se estabelece no espaço público, às vezes, de forma problemática, entre o conhecimento 
histórico e demais representações do passado. Sem hierarquiza-las, é necessário entender os espaços editoriais conferidos a cada uma delas, as possibilidades de divulgação de determinadas versões que se opõe a memórias e culturas históricas hegemônicas e as resistências decorrentes a uma possível incorporação destas novas interpretações ao quadro de uma "história nacional".

Além disto, é necessária uma relativização da liberdade de ensino, condicionada em grande parte, mas não somente, pelas proposições do projeto Escola Sem Partido, que falaciosamente denuncia uma ideologização do ensino e apregoa uma neutralidade na construção do conhecimento. Não irei me alongar explicitando os pormenores e as implicações do projeto, apenas ressaltar a tentativa de cerceamento dessa liberdade afirmada por Patto, bem como a possibilidade de que esse projeto fomente um relativismo exacerbado, ao defender um "pluralismo de concepções de mundo" que pode englobar versões criminosas, negacionistas e revisionistas sobre determinadas práticas, posturas e acontecimentos históricos.

Devemos estar atentos ao proselitismo político, mas não compactuar com uma equiparação entre todas as narrativas, como é salientado no texto da conferência:

Trocando em miúdos, a aceitação do pluralismo não inclui compactuar com preconceitos e diferentes formas de opressão, como o racismo, a violência contra as mulheres, a homofobia, a intolerância religiosa entre outros, que devem ser denunciados e combatidos. De igual forma, e isso é uma preocupação atual, devemos ter tolerância zero para os discursos autoritários que defendem o retorno à ditadura, sob qualquer pretexto (MOTTA 2016, p. 329).

Em outro trecho, o historiador cita uma das principais dificuldades do debate sobre um pluralismo de interpretações no espaço público, especificamente no ambiente escolar. Trata-se de um desafio que se explicita todas as vezes quando somos inquiridos sobre "quem tem razão" em uma controvérsia sobre determinado acontecimento, do desafio de ensinar que a história é construída a partir de versões, ou quando são apresentados os argumentos de liberdade de expressão e opinião para a disseminação de discursos de ódio, para além da apologia da ditadura civil-militar, que alimenta certo saudosismo em setores da sociedade brasileira:

Importante refletir sobre esse problema, também, tendo em vista a sua repercussão nos espaços de divulgação pública e de formação escolar. Considerando, em especial, o caso do ensino básico, o impacto do relativismo gera confusão e insegurança em relação ao valor do conhecimento histórico, além de disseminar a compreensão equivocada de que qualquer versão histórica tem igual valor (MOTTA 2016, p. 330).

Ainda sobre o espaço público, Patto faz referência à controvérsia sobre a participação de historiadores na composição da Comissão Nacional da Verdade, um dos temas que que mais polarizou as opiniões dos profissionais nos últimos tempos. Podem-se estabelecer paralelos nos debates ocorridos em 
países europeus em decorrência da presença de historiadores como peritos e testemunhas em processos judiciais contra crimes de lesa humanidade ou na investigação de ações revolucionárias (GINZBURG 1993; ROUSSO 1998).

Quanto à participação de historiadores na CNV, a ANPUH já havia se manifestado favoravelmente durante a gestão anterior, presidida por Benito Bisso Schmidt, no momento em que se aprovara a lei e se iniciara os debates sobre a composição da comissão. Nesse interregno, a associação realizou gestões para a indicação de um historiador para compor o grupo que seria responsável por coordenar os trabalhos de investigação e pesquisa.

Em nota intitulada "Comissão da Verdade: entre a memória e a história", divulgada no dia 12 de janeiro de 2012, no site da associação pela gestão 20112013, há um questionamento sobre os objetivos da comissão, que extrapolariam funções memoriais relativas à indenização e à reparação:

Porém, é preciso reconhecer que, se, por um lado, as reivindicações de cunho memorial são justificadas e importantes, elas não são suficientes. A memória é sempre ligada aos afetos, a identidades específicas, a sentimentos muitas vezes autocentrado do tipo: 'você não passou por isso, então não pode entender e julgar o que ocorreu'. Por isso, é tão importante que as lembranças sejam compreendidas à luz da História, forma de conhecimento do passado ligada à razão, ao intelecto, ao distanciamento, à tentativa de pensar o que ocorreu de maneira global e articulada. Obviamente, o historiador nunca é neutro e imparcial, ele também é sujeito de seu tempo. Porém, ao longo de sua formação, desenvolve habilidades como a pesquisa em arquivos, a crítica documental, a interpretação de testemunhos e a coleta e análise de fontes orais que Ihe permitem formular questões menos emocionais e mais balizadas por referências conceituais e metodológicas próprias de um conhecimento científico que tem por objetivo compreender, a partir da análise de fontes históricas, as tramas do passado (ainda que recente). Por esse motivo, a ANPUH - Associação Nacional de História, entidade que congrega aproximadamente quatro mil profissionais de História atuantes no ensino, na pesquisa e nas instituições voltadas à preservação do patrimônio, julga fundamental a participação de historiadores profissionais na Comissão da Verdade (ANPUH 2012, grifos no original).

E segue, salientando a autoridade dos historiadores para lidar com essas questões:

Eles têm o dever e a capacidade de pensar os temas tratados em tão importante fórum não apenas pelas lentes afetivas da memória, mas também pela perspectiva racional da História. Por isso, sua presença é imprescindível nos trabalhos da Comissão da Verdade e nos debates por ela suscitados que, com certeza, mobilizarão a sociedade brasileira no próximo ano (ANPUH 2012).

Pode-se afirmar que Patto corrobora esse posicionamento, embora não se manifeste diretamente à $\mathrm{CNV}$, mas sim quanto ao posicionamento de historiadores nesses debates:

[...] historiadores são constantemente chamados a tomar parte do debate.

E não deveriam se furtar a esse papel, que ao mesmo tempo provoca 
o dever profissional e toca a nossa obrigação cívica. O conhecimento histórico é importante elemento na formação da opinião política das pessoas e, nesse ponto, temos muito a oferecer (MOTTA 2016, p. 327).

Porém, como citado anteriormente, nem todos os profissionais foram favoráveis à participação de historiadores na comissão. Um dos exemplos mais notáveis foi de Carlos Fico, pesquisador da ditadura civil-militar, que se posicionou contrariamente em uma vídeo-palestra em seu blog.

A argumentação do historiador centrava-se na questão da verdade em história:

Comissões como essa tendem a constituir uma narrativa oficial, unívoca. As correntes teóricas, ao longo do século XX (como os Annales e o marxismo), lutaram exatamente contra isso e hoje, em termos epistemológicos, todos reconhecemos que a multiplicidade de interpretações co-possíveis é a base principal do processo social de construção de um conhecimento histórico eficaz, esclarecedor, que não se pretende uma "verdade", mas uma forma de entendimento que contribua para a compreensão refinada da experiência humana em toda a sua complexidade (FICO 2011).

Pela impossibilidade de sintetizar os múltiplos posicionamentos sobre o regime de verdade na história, cabe salientar que a posição tomada por Patto em sua conferência aproxima-o dos historiadores que creem na possibilidade de afirmação de uma verdade mínima sobre determinados acontecimentos, em um claro posicionamento contra o relativismo extremado, o revisionismo e o negacionismo:

Nos dias que correm, a questão da verdade não é debate restrito ao universo acadêmico, com repercussão somente nas polêmicas sobre os limites do conhecimento. Neste momento, em que estão em disputa representações sobre o passado recente de autoritarismo e violência, a demanda por verdade implica também desafios de ordem política e jurídica. Quando entram no foco da história os regimes autoritário-repressivos e, pensando de maneira mais ampla, qualquer forma de violência e opressão, os argumentos relativistas e hipercéticos, que são populares em alguns meios acadêmicos, revelam melhor as suas limitações. O investigador que atua nesse terreno não pode adotar o argumento relativista, ou seja, a posição de que discursos com pretensão à verdade devem ser desprezados como puro resquício do positivismo. A realidade é apenas um texto? Ela não passa de uma construção do historiador? Dá para aceitar tais postulados quando tratamos de temas como golpe de Estado, tortura, violência, trabalho escravo e censura? Não pode haver mesmo representações verdadeiras acerca da história? (MOTTA 2016, p. 329).

Novamente reforça-se a importância da participação dos historiadores nos debates públicos, agora argumentadas em função das implicações éticas deste posicionamento:

Vale a pena insistir sobre a manipulação em torno de 1964, pois muitos atores estão formando a opinião de certos grupos com base em representações ligeiras sobre a ditadura. Parece-me que aqui é fundamental a nossa atuação. Eis aí, portanto, um lugar chave para o 
historiador: o espaço público, o debate político, de que somos partes integrantes, inexoravelmente (MOTTA 2016, p. 328).

Nesta complexa interação entre ética, história e verdade, acredito que uma das principais contribuições vem de Mateus Pereira. Sem a pretensão de advogar por um monopólio do passado por parte da história, assim como o privilégio da condução dos debates públicos, pode-se adotar a postura recomendada pelo autor, de pensar a crítica histórica como uma função mediadora e qualificadora entre as diversas memórias e representações do passado presentes nas batalhas para conferir sentido ao passado, contribuindo "ao oferecer opções éticas melhores e mais justas a partir da sua função crítica" (PEREIRA 2015, p. 895). Em outras palavras, podemos pensar em um engajamento marcado pelo giro ético-político da história, sem desconsiderar alguns cânones científicos.

O terceiro e último lugar citado por Patto é o campo do ensino de história. Embora amparado nos debates dos projetos de lei que previam a reforma do ensino médio, sua fala datada de 2015 não previra que seria possível, em 2017, aprovarem o fim da obrigatoriedade do ensino de história nesse nível de ensino.

Embora minha posição seja contrária a essa reforma, acredito que algum tipo de modificação deveria ser feita no ensino médio, que, hoje em dia, se configura como uma mera repetição de conteúdos do ensino fundamental. Como afirmado por especialistas, a educação básica é um espaço de disputas políticas e de projetos educacionais.

Patto afirma que pensar a necessidade ou a obrigatoriedade do ensino de história significa refletir sobre o lugar da história e do historiador na sociedade de uma forma mais geral:

Por isso, reiterando, é necessário levantar questões que ajudem a pensar o nosso lugar na sociedade. Então, perguntemo-nos ainda uma vez: por que a história (por certo, a história acadêmica, crítica etc.)? Por que a sociedade e o Estado deveriam manter o lugar privilegiado que essa disciplina ocupa tradicionalmente? Ainda é justificável o investimento na história? Afinal, não estariam superados os contextos políticos que produziram o interesse pela história, em especial o impulso para construir identidades nacionais e fortalecer as organizações estatais correspondentes? Se o Estado nação que institucionalizou a história está em crise, também ela não estaria em vias de superação como campo de saber relevante? Se não há mais horizonte de expectativa e estamos condenados a um eterno presente e à memorialização nostálgica do passado, para que a história (MOTTA 2016, p. 333).

Nesse sentido, creio que deveríamos nos questionar, com sinceridade e sem receio a enfrentar a questão, de por que a história deve ser uma disciplina obrigatória na educação básica. Essa resposta está condicionada, inevitavelmente, às concepções de história, de sua função social, da crença em uma possibilidade de pedagogia do passado, etc, e a resposta dada pelo conferencista me parece bastante importante pela síntese que confere ao seu posicionamento ao longo da fala:

A história não é magistra vitae, impossível acreditar ainda nessa fórmula. Muitos atores nada aprenderam com a experiência do passado e repetiram 
os mesmos erros. Porém, o conhecimento histórico pode contribuir para a formação de cidadãos críticos, ao oferecer-Ihes oportunidade de analisar o seu lugar na experiência temporal e escolher caminhos de ação. A história ainda é indispensável para compreender o mundo e para fundamentar as decisões atuais, na medida em que coloca em perspectiva a experiência humana no tempo. Recuperando o que foi dito antes, como é possível a um cidadão formar sua opinião e valores políticos sem tomar como referência experiências passadas, mesmo que seja para recusá-las e buscar novas alternativas? A história não é mais necessária para construir a identidade nacional, pelo menos não no sentido que esse projeto teve no século XIX. Mas ainda é útil ao esforço de entender o que somos e a conjecturar sobre o que desejamos ser. A pesquisa histórica segue importante para entender esse pedaço do Globo a que chamamos Brasil. Como ele se formou em conexão com outros espaços da América, da África, da Europa e da Ásia? (MOTTA 2016, p. 333).

Por fim, gostaria de evidenciar duas ausências na fala de Rodrigo. A primeira, trata-se de uma renegação comum à área, que apenas recentemente despertou o interesse dos pesquisadores. Historiadores refletindo sobre sua prática e seus lugares de atuação; questões sobre a utilidade, sobre a função da história, e as dimensões éticas do papel social do historiador, enquanto produtor de narrativas históricas e cidadão; todas essas reflexões ocupam um espaço bastante significativo nos questionamentos sobre o ofício, mas pouco se fala sobre os posicionamentos dos historiadores frente às múltiplas temporalidades (AVELAR 2015).

Não menos importante, a segunda, em uma problematização mais ampla sobre lugares, não somente aqueles espaciais, diz respeito às mudanças ocorridas nos lugares que têm sido destinados na historiografia pelas ditas "minorias", que até bem pouco tempo ocupavam um não-lugar nas narrativas historiográficas. Para além da preocupação com os lugares de fala desses grupos, o aumento significativo de pesquisas sobre etnias, gênero, raça, sexualidade tem despertado uma série de problemáticas para os historiadores, como a intersecção da história profissional e seus procedimentos com a história pública, o academicismo e a militância, as dimensões éticas de determinadas representações do passado, etc.

O limite de páginas imposto a esse comentário, bem como a impossibilidade de uma resposta mais imediata, não permitiu que eu desenvolvesse uma questão que me acompanhou durante a escrita desse texto: por que em momentos de crise costuma-se voltar à discussão sobre o papel social do historiador, sobre suas ocupações, seus posicionamentos, etc.? O que esse incessante questionamento em períodos difíceis traduz? Estaríamos desiludidos com a possibilidade de aprendizado com a história, alimentando com essa postura certa melancolia? Consideraríamos a limitação de nossa ação como profissionais?

A apresentação desses questionamentos no penúltimo parágrafo desse texto é uma fuga consciente, como afirmei anteriormente, pela dificuldade em responder satisfatoriamente. Porém, mesmo que, como historiadora profissional, não predique previsões históricas, não faltarão crises para seguirmos nos questionando. 


\section{Referências bibliográficas}

ANPUH. Comissão da Verdade: entre a memória e a história. Disponível em: http://site.anpuh.org/index.php/2015-01-20-00-01-55/noticias2/ item/543-posicao-da-anpuh-sobre-a-participacao-dos-historiadores-nacomissao-da-verdade. Acesso em: 19 mar. 2017.

AVELAR, Alexandre de Sá. Rumo à indisciplinarização? Tempo histórico e a historiografia recente sobre o período militar. Disponível em: https://www.academia.edu/19973700/Rumo_\%C3\%A0_ indisciplinariza\%C3\%A7\%C3\%A30_Tempo_hist\%C3\%B3rico_e_a_ historiografia_recente_sobre_o_per\%C3\%ADodo_militar. Acesso em: 19 mar. 2017.

FICO, Carlos. Vídeo-palestra sobre Comissão da Verdade. Disponível em: http://www.brasilrecente.com/2011/11/videopalestra-sobre-comissaoda-verdade_19.html. Acesso em: 19 mar. 2017.

GINZBURG, Carlo. El juez y el historiador: consideraciones al margen del proceso Sofri. Madrid: Anaya, 1993.

HABERMAS, Jürgen. A constelação pós-nacional: ensaios políticos. São Paulo: Littera, 2001.

MOTTA, Rodrigo Patto Sá. Os lugares dos historiadores e da história na sociedade brasileira: Conferência de abertura do XXVIII Simpósio Nacional de História, Florianópolis. História da Historiografia, n. 22, p. 321-335, 2016.

PEREIRA, Mateus Henrique de Faria. Nova direita? Guerras de memória em tempos de Comissão da Verdade (2012-2014). Varia História, v. 31, n. 57, p. 863-902, 2015.

ROUSSO, Henry. La hantise du passé. Paris: Textuel, 1998. 